ticular tint of colour. The wave-length you see, in the distance from crest to crest of the waves travelling up the long model when I commence giving a simple harmonic oscillation to the lowest bar. I have here a convex lens of very long focus, and a piece of plate glass with its back blackened. When I press the piece of glass against the slass blackened behind, I see coloured rings; the phenomenon will be shown to you on the screen by means of the e'ectric light reflected from the space of air between the two pieces of glass. This phenomenon was first observed by Sir Isaac Newton, and was first explained by the undulatory theory of light. [Newton's rings are now shown on the screen before you by reflected electric light.] If I press the glasses together, you see a dark spot in the centre; the rings appear round it, and there is a dark centre with irregularities. Pressure is required to produce that spot. Why? The answer generally given is, because glass repels glass at a distance of two or three wave-lengths of light; say at a distance of $1 / 5,000$ of a centimetre. I do not believe that for a moment. The seeming repulsion comes from shreds or particles of dust between them.: The black spot in the centre is a place where the distance between them is less than a quarter of a wave-length. Now the wave-length for yellow light is about $1 / 17,000$ of a centimetre. The quarter of I/17,000 is about $1 / 70,000$. The place where you see the middle of that black circle corresponds to air at a distance of less than $\mathrm{r} / 70,000$ of a centimetre. Passing from this black spot to the first ring of maximum light, add half a wave-length to the distance, and we can tell what the distance between the two pieces of glass is at this place ; add another balf wave-length, and we come to the next maximum of light again; but the colour prevents us speaking very definitely because we have a number of different wave-lengths concerned. I will simplify that by reducing it all to one colour, red, by interposing a red glass. You have now one colour, but much less light altogether, because this glass only lets through homogeneous red light, or not much besides. Now look at what you see on the screen, and you have unmistakable evidence of fulcrums of dust between the glass surfaces. When I put on the screw, I whiten the central black spot by causing the elastic glass to pivot, as it were, round the innumerable little fulcrums constituted by the molecules of dust; and the pieces of glass are pressed not against one another, but against these fulcrums. There are innumerable-say thousands - of little particles of dust jammed between the glass, some of them of perhaps $1 / 3,000$ of a centimetre in diameter, say 5 or 6 wavelengths. If you lay one piece of glass on another, you think you are pressing glass on glass, but it is nothing of the kind; it is glass on dust. This is a very beautiful phenomenon, and my first object in showing this experiment was simply because it gives us a linear measure bringing us down at once to $1 / 100,000$ of a centimetre.

Now I am just going to enter a very little into detail regarding the reasons that those four lines of argument give us for assigning a limit to the smallness of the molecules of matter. I shall take contact electricity first, and very briefly. If I take these two pieces of zinc and copper and touch them together at the two corners, they become electrified, and attract one another with a perfectly definite force, of which the magnitude is ascertained from absolute measurements in connection with the well-established doctrine of contact electricity. I do not feel it, because the force is very small. You may do the thing in a measured way; you may place a little metallic knob or projection on one of them of $1 / 100,000$ of a centimetre, and lean the other against it. Let there be three such little metal feet put on the copper; let me touch the zinc plate with one of them, and turn it gradually down till it comes to touch the other two. In this position, with an air-space of $\mathrm{I} / \mathrm{IO0}, 000$ of a centimetre between them, there will be positive and negative electricity on the zinc and copper surfaces respectively, of such quantities as to cause a mutual attraction amounting to 2 grammes weight per square centimetre. The amount of work done by the electric attraction upon the plates while they are being allowed to approach one another with metallic connection between them at the corner first touched, till they come to the distance of $1 / 100,000$ of a centimetre, is $2 / 100,000$ of a centimetre-gramme, supposing the area of each plate to be one square centimetre.

(To be continued.)

\section{DEATH OF THE PRESIDENT OF THE ROYAL SOCIETY}

$\mathrm{T}$ is with the profoundest regret that we announce the death of Mr. Spottiswoode, the President of the Royal Society, at Ir.I 5 yesterday morning. The bulletin issued on Tuesday to the effect that although there was no hemorrhage, still that there was no improvement in Mr. Spottiswoode's condition, boded ill because those who knew him best feared that a reserve of strength, which might perhaps have made way against the further progress of the fever through its later stages, was wanting.

As the sad news reaches us just as we are going to press, and as indeed we so recently entered at some considerable length into the lifework of him who is now no more, there is no necessity for us on the present accasion to do more than make the above announcement. This, however, must be said: that there is hardly a man of science in this country, and there are very many in other countries, who will not feel that they have lost a true friend, and one of whose friendship any man might have been proud. There is little doubt too that if he had been more sparing of himself in the various duties which were incumbent upon him as President of the Royal Society, if he had not so freely given all his thoughts and all his exertions to any scientific question which was going on, there might bave been more time for relaxation, and there might have been strength to have tided over the illness which has now laid him low.

\section{NOTES}

WE regret to have to announce the death of General Sir Edward Sabine, K.C. B., which occurred on the 26 th inst. at Richmond, where he had been residing for the last twelve months. $\mathrm{He}$ was in his ninety-fifth year, having been born October 14, I788.

At the meeting of the Paris Academy of Sciences on Monday last week the following message concerning the eclipse observations from M. Janssen, dated San Francisco, was read:" Fanssen: discovery of the Fraunhofer spectrum and the dark lines of the solar spectrum in the corona, showing cosmical matter around the sun. Large photographs of the corona and the circumsolar regions to a distance of $15^{\circ}$, in search for intraMercurial planets. Palisa and Trouvelot: Exploration of the circumsolar regions; no intra-Mercurial planets found. Trouvelot: Sketch of the corona. Tacchini: Polarisation of the corona and streamers; spectrum of the streamers, showing analogy 